\title{
A critical reappraisal of bilateral adrenalectomy for ACTH-dependent Cushing's syndrome
}

\author{
Martin Reincke, Katrin Ritzel, Andrea Oßwald, Christina Berr, Günter Stalla ${ }^{1}$, \\ Klaus Hallfeldt ${ }^{2}$, Nicole Reisch, Jochen Schopohl and Felix Beuschlein
}

Medizinische Klinik und Poliklinik IV, Klinikum der Ludwig-Maximilians-Universität München, Ziemssenstraße 1, D-80336 Munich, Germany, ${ }^{1}$ Max-Planck-Institut für Psychiatrie, Munich, Germany and ${ }^{2}$ Chirurgische Klinik und Poliklinik - Innenstadt, Klinikum der Ludwig-Maximilians-Universität München, Munich, Germany
Correspondence should be addressed to M Reincke

Email

Martin.Reincke@med. uni-muenchen.de

\begin{abstract}
Objective: Our aim was to review short- and long-term outcomes of patients treated with bilateral adrenalectomy (BADx) in ACTH-dependent Cushing's syndrome.

Methods: We reviewed the literature and analysed our experience with 53 patients treated with BADx since 1990 in our institution.

Results: BADx is considered if ACTH-dependent Cushing's syndrome is refractory to other treatment modalities. In Cushing's disease (CD), BADx is mainly used as an ultima ratio after transsphenoidal surgery and medical therapies have failed. In these cases, the time span between the first diagnosis of $C D$ and treatment with BADx is relatively long (median 44 months). In ectopic Cushing's syndrome, the time from diagnosis to BADx is shorter (median 2 months), and BADx is often performed as an emergency procedure because of life-threatening complications of severe hypercortisolism. In both situations, BADx is relatively safe (median surgical morbidity $15 \%$; median surgical mortality $3 \%$ ) and provides excellent control of hypercortisolism; Cushing's-associated signs and symptoms are rapidly corrected, and co-morbidities are stabilised. In CD, the quality of life following BADx is rapidly improving, and long-term mortality is low. Specific long-term complications include the development of adrenal crisis and Nelson's syndrome. In ectopic Cushing's syndrome, long-term mortality is high but is mostly dependent on the prognosis of the underlying malignant neuroendocrine tumour.

Conclusion: BADx is a relatively safe and highly effective treatment, and it provides adequate control of long-term co-morbidities associated with hypercortisolism.
\end{abstract}

\section{Invited Author's profile}

Prof. Martin Heinrich Reincke is Director of the Medizinische Klinik and Poliklinik IV, Ludwig-MaximiliansUniversität München, and Chair of the Department of Endocrinology and Diabetology. His research specialities include adrenal physiology and pathophysiology, endocrine hypertension, pituitary disease, mineralocorticoid and glucocorticoid action and stress research. Professor Reincke heads a research team that specifically explores the prevalence and relevance of Cushing's syndrome at the epidemiological, clinical, genetic and molecular levels. The research teams of his clinic have particular expertise in assay development and validation for endocrine disease and in the development of genetically manipulated animals as models for human adrenal disease.

(c) 2015 European Society of Endocrinology Printed in Great Britain Published by Bioscientifica Ltd.
This article is adapted from work presented at IMPROCUSH-1, 12-14 October 2014 The meeting was supported by the European Science Foundation, Deutsche Forschungsgemeinschaft, Carl Friedrich von Siemens Stiftung, European Neuroendo-

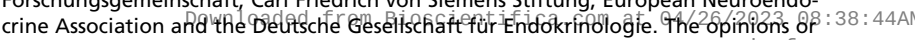
views expressed in this article are those of the authors, and do not necessarily reflecte access the opinions or recommendations of the supporters of the symposium. 


\section{Introduction}

Endogenous Cushing's syndrome is defined as chronic exposure to inadequate high levels of plasma cortisol. Cushing's syndrome is rare, with an estimated annual incidence that ranges from 1.2 to 2.7 per million $(1,2)$. The stigmata of Cushing's syndrome include phenotypic changes in fat distribution (truncal obesity, moon face, etc.), myopathy and skin manifestations, such as plethora, skin fragility and infections, ecchymosis and striae. The signs and symptoms of Cushing's syndrome overlap with those that occur in patients with the metabolic syndrome. Because of the epidemic dimension of the metabolic syndrome, in Western societies, identifying Cushing's syndrome in an early stage is becoming increasingly challenging.

Cushing's syndrome is divided by aetiology into adrenocorticotrophin (ACTH)-dependent and ACTHindependent forms. In the former, pituitary corticotroph adenomas and ectopic ACTH-producing neuroendocrine tumours cause hypercortisolism by stimulating both adrenals. The majority of the ACTH-independent causes of Cushing's syndrome are unilateral adrenal adenomas and, much less frequently, carcinomas. Rare causes of adrenal Cushing's syndrome include macro- and micronodular bilateral adrenal hyperplasia. Macronodular and micronodular hyperplasia mostly affect both glands equally. Table 1 shows the distribution by aetiology in our own institution from 1990 to 2014.

Bilateral adrenalectomy (BADx) is a complex surgical procedure that results in a lifelong dependency on glucocorticoid substitution and a risk of developing Nelson's syndrome. On the other hand, BADx is an essential treatment option for patients with Cushing's syndrome when previous treatments have failed. We have recently systematically evaluated the immediate outcome and the long-term consequences of BADx in Cushing's syndrome (3) and reported our results in 36 patients treated with BADx in Munich (4). The present review addresses the practical aspects of BADx and is based on recent evidence and the outcome of $53 \mathrm{BADx}$ treatments in our institution.

\section{Primary goal in Cushing's syndrome: control of hypercortisolism by surgery}

The primary treatment goal in patients with endogenous Cushing's syndrome is to terminate excess cortisol production by removing the autonomous ACTH or cortisol-producing tumour tissue without permanently damaging the pituitary-adrenal axis.

First-line treatment of ACTH-independent Cushing's syndrome that results from an adrenal adenoma is unilateral adrenal surgery. In contrast, bilateral micro- or macro-nodular adrenal hyperplasia is treated by BADx, although there have been recent reports of successful long-term outcomes following unilateral adrenalectomy in selected patients $(5,6)$.

In ACTH-dependent forms of Cushing's syndrome, the first-line treatment focuses on the surgical removal of the site of ACTH production (7). Transsphenoidal microsurgery has become the primary treatment for Cushing's disease (CD) when ACTH response to corticotrophinreleasing hormone, imaging and/or inferior petrosal sinus sampling indicate pituitary ACTH production. Transsphenoidal surgery by an expert neurosurgeon achieves remission in $42-97 \%$ of cases (median 78\%) (reviewed by Petersenn et al. (8)). Remission and recurrence rates after transsphenoidal surgery vary widely and are influenced by pituitary morphology, the invasiveness of the pituitary tumour, the patient's age and the experience of the surgeon. In a significant percentage of patients,

Table 1 Causes of Cushing's syndrome, rate of BADx and surgical mortality in the endocrinology department, Medizinische Klinik IV, Klinikum der Ludwig-Maximilians-Universität, from 1990 to 2014.

\begin{tabular}{|c|c|c|c|}
\hline Cause of Cushing's syndrome & $n(\%)$ & $\begin{array}{l}\text { Patients treated by } \\
\text { BADx }(n(\%))\end{array}$ & $\begin{array}{l}\text { Surgical (30-day) } \\
\text { mortality of BADx }\end{array}$ \\
\hline ACTH-dependent Cushing's syndrome & $184(74)$ & & \\
\hline Cushing's disease & $154(62)$ & $34(22)$ & 1 \\
\hline Ectopic Cushing's syndrome & $30(12)$ & $11(37)$ & 0 \\
\hline ACTH-independent Cushing's syndrome & $64(26)$ & & \\
\hline Cortisol-producing adenoma & 46 (19) & 0 & 0 \\
\hline Cortisol producing carcinoma & $5(2)$ & 0 & 0 \\
\hline Bilateral adrenal hyperplasia & $13(5)$ & $8(61)$ & 1 \\
\hline Total & $248(100)$ & $53(21)$ & $2(4)$ \\
\hline
\end{tabular}


hypercortisolism persists or recurs after a few years. Recurrence occurs in $3-47 \%$ of cases, with a median of $12 \%(8)$, and there are higher recurrence rates with longterm follow-up.

The primary approach to ACTH-producing neuroendocrine tumours that cause ectopic Cushing's syndrome is resection or tumour debulking. In this context, $\mathrm{BADx}$ is applied in two situations: In 8-16\% of patients, the primary tumour site cannot be identified and remains occult during follow-up $(9,10,11)$. The second common clinical situation is the incomplete removal of the tumour, local recurrences or metastatic disease without further surgical options, and this occurs in $71-88 \%$ of patients $(9,10)$.

\section{Treatment options in persistent or recurrent CD: the case for BADx}

As indicated in the previous section, persistence and recurrence in $\mathrm{CD}$ affects a substantial percentage of patients. According to a meta-analysis by Petersenn et al. (8), $31 \%$ of patients are in need of secondary treatment options, either because they are not controlled by a first pituitary surgery ( $22 \%$ of patients) or because they develop recurrence (9\% of patients). Second-line therapeutic options consist of second transsphenoidal surgery, pituitary irradiation, medical therapy and BADx. Each of these strategies has advantages and disadvantages (Fig. 1) that have been recently reviewed $(7,12)$. In many instances, they are used in combination or sequentially.

Repeat transsphenoidal surgery is advocated in most centres but has a lower success rate and a higher recurrence rate than first surgery does. Remission rates may be as high as $70 \%$ in selected patients in highly specialised centres (7). However, more recent series report a lower success rate of around $40 \%$ (13). In a recent study of 64 patients with persistence or recurrence, $43 \%$ did not undergo repeat surgery surgical because of tumour invasion into the cavernous sinus, which was not amendable to complete resection, because of other contraindications to surgery or because of patient preference. In total, 36 patients underwent repeat transsphenoidal surgery, and remission was achieved in $42 \%$. Second recurrence occurred in $40 \%$ of patients after a mean of 27 months (14). In our institution, we consider second transsphenoidal surgery in all cases of persistent or recurrent CD following a careful review by our multidisciplinary pituitary tumour board.

Second-line treatment by pituitary radiation is widely used if repeated transsphenoidal surgery fails or is not feasible. In one previous study, fractionated radiotherapy was shown to have induced remission in 60 percent at 18 months and 91 percent at 5 years follow-up, but also hypopituitarism in $57 \%$ of patients (15). Cranial nerve neuropathy occurred in up to $5 \%$ of patients. Stereotactic radiosurgery appears to have lower success rates (16): in one

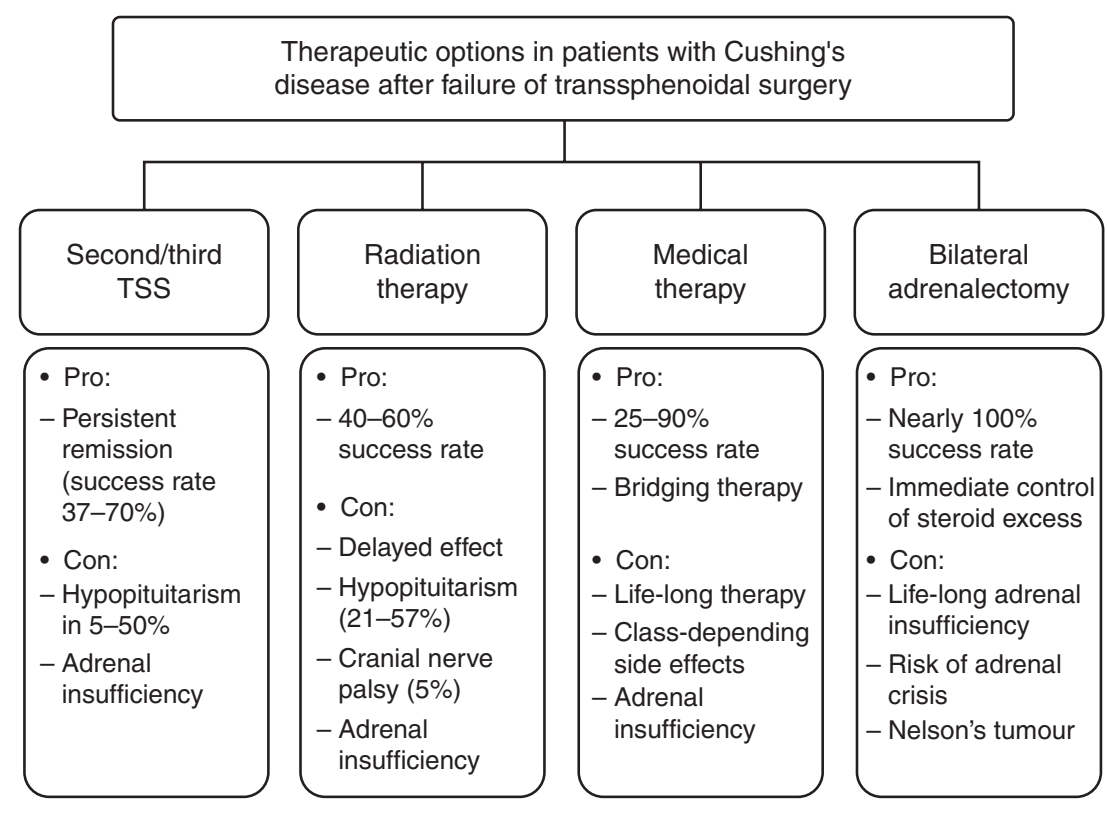

Figure 1

Strategies in recurrent or persistent Cushing's disease after first transsphenoidal surgery. TSS, transsphenoidal surgery. 
study that included 18 patients with $\mathrm{CD}, 50 \%$ of the patients were in remission after 28 months, two patients developed recurrence after 6 and 8 years and 21\% of patients developed hypopituitarism during the observation period (17). Our institution uses fractionated pituitary radiation and stereotactic radiosurgery mainly for local tumour control of growing corticotroph tumours but not for biochemical control of Cushing's syndrome.

Medical therapies have been used for 50 years in Cushing's syndrome with variable success. Evidence of success has mainly been based on retrospective case series, and efficacy has rarely been assessed prospectively in randomised controlled trials. This has recently changed because three drugs were formally approved for the treatment of Cushing's syndrome. Several further compounds are currently under investigation. Pituitarydirected approaches include the dopamine agonist cabergoline (18) and the multi-receptor somatostatin-analogue pasireotide (19). Inhibitors of steroidogenesis that inhibit cytochrome $\mathrm{P} 450$ enzymes include metyrapone, ketoconazole and LCI699 $(20,21)$. Hypercortisolism can also be controlled by the adrenolytic agent mitotane $(22,23,24)$ and by the glucocorticoid receptor antagonist mifepristone (25). Currently, the approved drugs have limited efficacy because monotherapies and side effects limit their long-term use. A combination of several pituitary and adrenal-directed therapeutic approaches has been shown to increase efficacy (26), but long-term outcome has not been well established. Therefore, the exact status of medical treatment remains to be defined and is evolving. In many places, including our institution, medical treatment is frequently used as an adjunctive or bridging measure until definite therapy can be performed.

\section{When is BADx in ACTH-dependent Cushing's syndrome indicated?}

In general, two scenarios can be distinguished: elective and emergency BADx. Elective BADx is used in patients with $\mathrm{CD}$ in whom the ACTH excess is not amendable to other second-line treatments. In such a setting, BADx is generally considered to be the ultima ratio after other attempts to establish safe cortisol levels have failed or have been contraindicated. The latter may be the case in a female patient with $\mathrm{CD}$ who wishes to become pregnant and cannot be treated medically or by pituitary radiation. It is typical that time until BADx for patients in this category is rather long. In fact, in the Munich cohort of 34 CD patients, the median time between diagnosis of $C D$ and BADx was 44 months. The patients underwent BADx after one $(62 \%)$ or several (38\%) transsphenoidal surgeries, radiation (21\%) and medical therapies (45\%) (4).

Emergency BADx is performed in patients with very severe Cushing's syndrome. The characteristic scenario in this category consists of patients with massive ACTH and cortisol excess, which causes the most severe forms of Cushing's syndrome. These patients typically suffer from ectopic Cushing's syndrome. They might develop, in addition to classical Cushing's stigmata, life-threatening complications of hypercortisolism, such as bacteraemia and sepsis $(27,28,29)$, thromboembolic complications, intractable hypokalaemic hypertension, heart failure, gastrointestinal haemorrhage, psychosis, debilitating myopathy, uncontrolled hyperglycaemia or a combination of these conditions (30). Serum cortisol levels generally reach $41 \mu \mathrm{g} / \mathrm{dl}(1100 \mathrm{nmol} / \mathrm{l})$ and may be even higher than $100 \mu \mathrm{g} / \mathrm{dl}(2700 \mathrm{nmol} / \mathrm{l})$. Emergency BADx can also be indicated after long periods of uncontrolled $\mathrm{CD}$ that have led to catastrophic situations with debilitating complications (stroke, myocardial infarction, osteoporotic fractures, etc.), even when cortisol secretion is not extremely high. In such a situation, the duration of uncontrolled hypercortisolism is the damaging factor. Timing of BADx is important because the course is generally fatal if hypercortisolism cannot be controlled and BADx is delayed or postponed (30). Therefore, we use the term 'malignant' or 'catastrophic' Cushing's syndrome to characterise this emergency scenario, and in such cases,

Table 2 Diagnostic criteria and specific treatment of emergency BADx in catastrophic Cushing's syndrome.

Clinical criteria

A patient with Cushing's syndrome and recent onset of one or more of the following:

- sepsis, opportunistic infection;

- intractable hypokalaemia, uncontrolled hypertension;

- heart failure;

- gastrointestinal haemorrhage;

- glucocorticoid-induced acute psychosis;

- progressive debilitating myopathy;

- thromboembolism; and/or

- uncontrolled hyperglycaemia and ketoacidosis.

Biochemical criteria

A patient with Cushing's syndrome and at least one of the following conditions:

- serum cortisol of $\geq 41 \mu \mathrm{g} / \mathrm{dl}$ (1100 $\mathrm{nmol} / \mathrm{l})$ (27); and/or

- severe hypokalaemia $(<3.0 \mathrm{mmol} / \mathrm{l})$.

Treatment

Consider transfer to ICU

Control hypercortisolism with $2.5-3.0 \mathrm{mg} / \mathrm{h}$ etomidate i.v. (safe cortisol levels: in physiologically stressed patients, 500-

$800 \mathrm{nmol} / /$; in non-stressed patients, $150-300 \mathrm{nmol} / \mathrm{l}$ ) (31)

Treat complications

Plan BADx at the next available possibility 
BADx has to be performed in the shortest possible time span. Table 2 summarises the signs and symptoms of catastrophic Cushing's syndrome and the action that was taken. As expected, the median time from the diagnosis of ectopic Cushing's syndrome to BADx was short, at 4 months (4). Our approach to patients with catastrophic Cushing's syndrome who are scheduled for BADx includes a pre-surgical phase that aims to stabilise the patient with parenteral adrenostatic treatment. The patient is treated for 5-10 days with the 11ß-hydroxylase inhibitor etomidate in a non-sedative dose. I.v. low-dose etomidate infusion rates for the treatment of hypercortisolaemia are $0.04-0.05 \mathrm{mg} / \mathrm{kg}$ per $\mathrm{h}$, which equates to $2.5-3 \mathrm{mg} / \mathrm{h}$ with dose titration according to serum cortisol levels (31), and a maximum dose of up to $5 \mathrm{mg} / \mathrm{h}$ in selected cases. Based on the pharmacokinetic properties of etomidate, cortisol levels fall within 12-24 h (32). Monitoring of serum cortisol levels is necessary to achieve the desired blockade and to prevent hypoadrenalism. The aim is to titrate serum cortisol levels to $500-800 \mathrm{nmol} / 1$ in physiologically stressed patients and to $150-300 \mathrm{nmol} / \mathrm{l}$ in unstressed patients (31). The treatment goals depend on the patient's presentation, and they include the normalisation of hypokalaemia, the control of hypertension and myopathy, the amelioration of psychosis and immunosuppression. Whether ICU stay during etomidate application should be mandatory remains controversial $(31,33)$. Our approach requires the initiation of etomidate in the ICU for 2 days and transfer to a normal ward thereafter when cortisol levels are in a safe and stable range and surgery cannot be performed immediately.

An alternative to i.v. etomidate followed by emergency BADx might be an oral combination therapy that consists of mitotane, metyrapone and ketoconazole. The two fast-acting steroidogenesis inhibitors metyrapone and ketoconazole provide rapid clinical and biological control of severe hypercortisolism, which thus covers the lag period before mitotane starts to act. The safety and efficacy of this regimen has been demonstrated recently (23). In that study, all 11 patients had ACTH-dependent Cushing's syndrome associated with clinical disorders such as severe cardiovascular, respiratory or infectious complications that precluded the surgical removal of the source of excessive ACTH as well as bilateral surgical adrenalectomy. UFC excretion fell within $48 \mathrm{~h}$ after the initiation of oral steroidogenic blockade into the normal range and remained controlled long-term. Five of the 11 patients eventually underwent successful transsphenoidal surgery. Rapid control of hypercortisolism was reported when a combination of metyrapone and ketoconalzole was used in 14 patients with ectopic Cushing syndrome and in eight patients with adrenocortical carcinomas. After 1 week of treatment, median $24 \mathrm{~h}$ urinary cortisol fell from 40 to three times the upper limit of normal in the patients with ectopic Cushing's syndrome and from 16 to one times the upper limit of normal in patients with adrenocortical carcinomas respectively. After 1 month of treatment, 73 and $86 \%$ of patients were controlled respectively (34).

\section{Surgical outcome}

Laparoscopic adrenalectomy was introduced in 1992 (35), and it has now replaced the open posterior and anterior approaches, which are associated with more wound complications and prolonged hospital stays. Only a small number of studies have directly compared open vs laparoscopic bilateral procedures in patients with Cushing's syndrome $(36,37,38)$. Those studies demonstrated reduced blood loss and shortened hospital stays but similar mortality, morbidity and quality of life. Currently, the most commonly used technique is simultaneous bilateral laparoscopic BADx with the lateral transabdominal transperitoneal laparoscopic approach, although posterior retroperitoneoscopic adrenalectomy is advocated in some centres $(30,39)$ Because of the severe co-morbidities and the bilateral approach, patients with Cushing's syndrome have a higher risk for surgery-related morbidity and mortality than do patients with
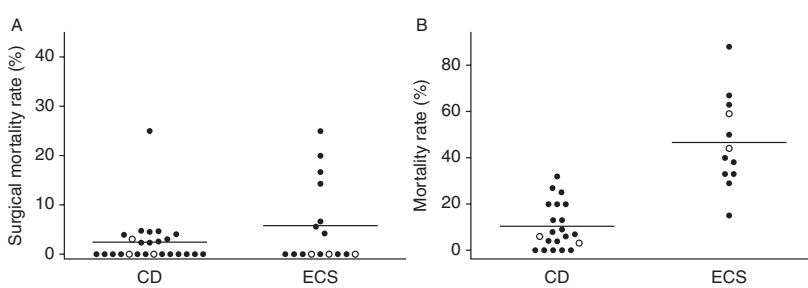

\section{Figure 2}

Mortality in patients with ACTH-dependent Cushing's syndrome following BADx. (A) Surgical (30-day) mortality. (B) Long-term mortality after undergoing BADx. The closed circles represent data from the 2013 systematic review by Ritzel et al. (3). The open circles depict studies published since 2013, including surgical mortality $(4,30,41)$ and total mortality $(4,30)$. Mortality is lower in studies that involved patients with Cushing's disease than it is in patients with ectopic Cushing syndrome (surgical mortality 2.4 vs $5.7 \%$ respectively; total mortality 10.2 vs $46.3 \%$ respectively). CD, Cushing's disease; ECS, ectopic Cushing syndrome. 
pheochromocytoma or aldosterone-producing adenomas who undergo unilateral adrenalectomy (40). Fig. 2A summarises the studies that have examined the surgical mortality of BADx in patients with Cushing's syndrome. As evident from Fig. 2A, patients with ectopic Cushing's syndrome have an adverse outcome because of more severe hypercortisolism and an underlying malignant tumour (CD: $2.1 \%$ vs ectopic Cushing's syndrome: $3.6 \%$ ).

\section{Long-term mortality}

Long-term mortality is reported heterogeneously, as has been pointed out in the review by Ritzel et al. (3). Figure $2 \mathrm{~B}$ shows non-adjusted mortality data of BADx in ectopic Cushing's syndrome (12 studies) as compared to CD (21 studies). Ectopic Cushing's syndrome is associated with higher mortality, likely as a result of the progression of the underlying malignancy. We recently reported that long-term mortality in a large series $(n=50)$ with a long follow-up was $14 \%$ (4). The Kaplan-Meier curve (Fig. 3) showed excellent survival in CD (mortality at $1,2,5$ and 10 years: $2.9 \%$ ). Mortality was high in ectopic Cushing's syndrome (22\% at 1 year and $44 \%$ at 2 , 5 and 10 years).

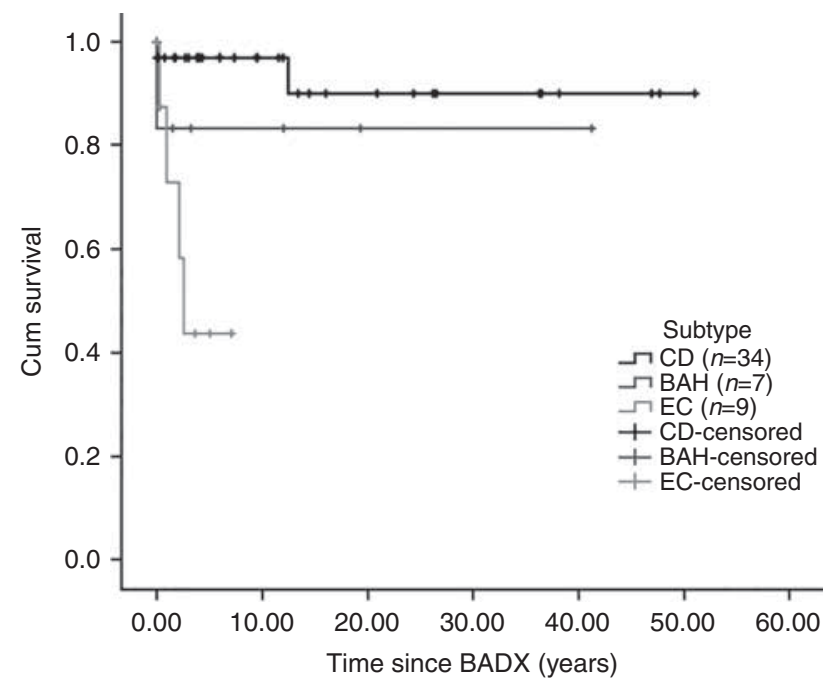

\section{Figure 3}

Long-term mortality of the Munich cohort (reprinted with permission from the European Society of Endocrinology from Osswald et al. (4)). Survival in patients with Cushing's syndrome according to Cushing's subtype (Kaplan-Meier method). $\mathrm{CD}$, Cushing's disease; $\mathrm{BAH}$, bilateral adrenal hyperplasia; ECS, ectopic Cushing's syndrome.

\section{Clinical outcomes and complications}

BADx is an effective means of reducing Cushing'sassociated morbidity. Because of the immediate termination of glucocorticoid excess, its effect becomes evident instantly. All of the studies reviewed by Ritzel et al. (3) showed partial or full remission of Cushing'sassociated signs and symptoms. Phenotypic stigmata decreased in $85 \%$ of the patients, arterial hypertension decreased in $82 \%$ and diabetes mellitus decreased in $70 \%$. Symptoms and co-morbidities such as obesity, depression and muscle weakness showed the lowest overall remission rate of $32-43 \%$. According to Sipple et al. (41) hypertension, obesity and depression improved in 7-10 months, whereas weakness and acne persisted for 12-17 months. Although functional remnant or ectopic adrenal tissue has been reported in some studies, clinical recurrence of Cushing's syndrome after BADx is very rare, at $<2 \%$ (3). However, in a recent study, three out of 21 patients had clinical recurrence based on unilateral or bilateral single adrenal bed nodules (30).

Five studies have formally addressed quality of life after successful BADx in patients with Cushing's syndrome $(4,38,42,43,44)$. Significant improvement in quality of life after BADx was achieved in $82-89 \%$ of the patients. Although quality of life in patients with Cushing's syndrome significantly improved in all of the studies after BADx, it was still definitely and permanently reduced as compared to a matched healthy control population $(4,43,44)$. This appears to be unrelated to BADx itself, seeing as patients with $\mathrm{CD}$ following successful transsphenoidal surgery are similarly affected by an impaired quality of life.

Procedure-related long-term complications after BADx include adrenal crisis and Nelson's syndrome. Addisonian crisis is caused by a total lack of endogenous glucocorticoid production. It can be prevented by glucocorticoid substitution with an adequate increase in dosage in situations of increased physical stress (45). As in all patients with adrenal insufficiency, patients who are treated with BADx should undergo structured education. Table 3 shows the incidence of adrenal crisis in patients after BADx. Incidences of 4.1-9.1 per 100 patient-years are within the range of adrenal crisis that results from other causes of glucocorticoid deficiency, such as Addison's disease, secondary adrenal insufficiency and congenital adrenal hyperplasia $(46,47,48)$.

Nelson's syndrome is a potentially life-threatening condition that can occur following BADx for the treatment of CD (49). The diagnosis of Nelson's syndrome has 
Table 3 The incidence of adrenal crisis in patients after BADx as compared to other causes of adrenal insufficiency.

\begin{tabular}{|c|c|}
\hline Author & Study type \\
\hline \multicolumn{2}{|l|}{ BADx } \\
\hline Ritzel et al. (3) & $\begin{array}{l}\text { Retrospective } \\
\text { (review of six } \\
\text { manuscripts) }\end{array}$ \\
\hline Osswald et al. (4) & Retrospective \\
\hline
\end{tabular}

Primary and secondary adrenal insufficiency Hahner et al. (45) Retrospective 444

Hahner et al. (46) Prospective

434

Congenital adrenal hyperplasia Reisch et al. (47) Retrospective

122

\section{Causes of adrenal}

No.

203

insufficiency

BADx

50 BADx

$\mathrm{CAH}$

Primary Al, $n=254$; secondary $\mathrm{Al}_{\mathrm{t}}$ $n=190$

Primary $\mathrm{Al}, n=221$; secondary $\mathrm{Al}$, $n=202$

\section{Median follow-up} (months)

42

132

6092 patient-years

24 months (768 patient-years)

\begin{tabular}{|c|c|}
\hline Addison's crisis & Death \\
\hline $\begin{array}{l}9.3 \text { per } 100 \\
\text { patient-years }\end{array}$ & ND \\
\hline $\begin{array}{l}4.1 \text { per } 100 \\
\text { patient-years }\end{array}$ & $\begin{array}{c}1(2 \%)(0.2 \text { per } 100 \\
\text { patient-years })\end{array}$ \\
\hline $\begin{array}{c}6.3 \text { crises per } 100 \\
\text { patient-years }\end{array}$ & Not reported \\
\hline $\begin{array}{l}8.3 \text { crises per } 100 \\
\text { patient-years }\end{array}$ & $\begin{array}{c}4(0.9 \%)(0.5 \text { adre- } \\
\text { nal crisis-related } \\
\text { deaths per } 100 \\
\text { patient years) }\end{array}$ \\
\hline $\begin{array}{l}5.8 \text { crises per } 100 \\
\text { patient-years; } \\
\text { salt wasting: } \\
8.8 ; \text { simple } \\
\text { virilising: } 2.5\end{array}$ & Not reported \\
\hline
\end{tabular}

Al, adrenal insufficiency; ND, not determined.

changed over the past few decades. In early studies, the detection of Nelson's syndrome depended on clinical observation and conventional scull radiography. Thus, tumours were frequently diagnosed late in their clinical manifestation. With the more widespread application of tomographic imaging modalities, the direct identification of tumours has become possible at an earlier stage. An additional variable that has influenced the incidence of Nelson's syndrome in different studies is the length of follow-up, seeing as Nelson's syndrome can occur as late as 24 years after BADx (50). The incidence of Nelson's syndrome that occurred following BADx in 24 studies with 768 patients ranged from 0 to $47 \%$, with a median of $21 \%$ and a median follow-up of 61 months (3). Nelson tumours occurred in 24\% (7/29) of our patients with CD (4) and required repeated transsphenoidal surgery and radiation therapy. In all instances, Nelson's syndrome could be well controlled by these measures. A recent study by Assié et al. (51) conceptually revised the often arbitrary criteria that is used to define Nelson's syndrome (the presence of a pituitary adenoma and high ACTH concentration). Using short pituitary MRI imaging intervals (median 12.4 months) in 53 patients, they evaluated corticotroph tumour progression during a median followup after adrenalectomy of 4.6 years. Corticotroph tumour progression was defined as the occurrence of an adenoma in a patient without visible adenoma at baseline MRI or by the progression of an existing adenoma. Three years after adrenalectomy, the proportion of patients who presented with corticotroph tumour progression reached 39\%, and the proportion plateaued at $47 \%$ after 7 years. In multivariate analysis, a shorter duration of hypercortisolism and high plasma ACTH concentration in the 1st year after adrenalectomy were found to be independent predictive factors for corticotroph tumour progression. That study demonstrates that corticotroph tumour progression is not constant; rather, it occurs early after BADx and is predictable by ACTH determination and close MRI monitoring.

\section{Conclusion}

BADx is used in two instances: elective adrenalectomy in $\mathrm{CD}$ as an ultima ratio after the failure of (repeated) transsphenoidal surgery, pituitary radiation, medical therapy or a combination of these therapies and in cases of contraindications (pregnancy, side effects of medication, etc.). In these situations, many years have typically elapsed between the first diagnosis of Cushing's syndrome and the final decision to perform BADx. In contrast, emergency adrenalectomy in severe, life-threatening (so-called 'catastrophic') Cushing's syndrome is a medical emergency. In this situation, BADx is often performed shortly after a diagnosis of Cushing's syndrome has been 
established. Patients typically suffer from ectopic Cushing's syndrome that is either caused by an aggressive neuroendocrine tumour or by an occult ACTH source. Clinically, patients have a high risk of severe complications, such as infections, myopathy, hyperglycaemia, psychosis or hypokalaemic hypertension. In both elective and in emergency BADX, the surgical procedure can be performed with manageable morbidity and a 30-day mortality in the lower single-digit range. Long-term outcome depends on the underlying cause of ACTH hypersecretion. In refractory $\mathrm{CD}$, long-term outcome is excellent and can be superior to medical treatment (30). The available data support early use of BADx in (ACTHdependent) Cushing's syndrome. In ectopic Cushing's syndrome, the overall prognosis is limited by the biological behaviour of the underlying malignancy. More than $40 \%$ of patients have died after 24 months, mainly because of tumour progression. In ectopic Cushing's syndrome, life expectancy and procedure-related complications have to be carefully weighed. In summary, BADx is a safe and highly effective therapy for ACTHdependent Cushing's syndrome. Its effectiveness has been proven in elective BADx and in the most severe forms of ectopic Cushing's syndrome. It is our conviction that BADx should be used more frequently.

\section{Declaration of interest}

The authors declare that there is no conflict of interest that could be perceived as prejudicing the impartiality of the review.

\section{Funding}

The symposium was sponsored by unrestricted scientific grants from the DFG (grant number Re 752/22-1), the European Science Foundation (grant number 5551) and the Carl Friedrich von Siemens Stiftung. M Reincke was supported by a grant from the Else Kröner-Fresenius Stiftung (grant number 2012_A103).

\footnotetext{
Acknowledgements

This paper forms part of a special issue of European Journal of Endocrinology on Cushing's syndrome. This article is adapted from work presented at the IMPROCUSH-1: Improving Outcome of Cushing's Syndrome symposium, 12-14 October 2014. The meeting was supported by the European Science Foundation, Deutsche Forschungsgemeinschaft, Carl Friedrich von Siemens Stiftung, European Neuroendocrine Association and the Deutsche Gesellschaft fur Endokrinologie. The opinions or views expressed in this special issue are those of the authors, and do not necessarily reflect the opinions or recommendations of the European Science Foundation, Deutsche Forschungsgemeinschaft, Carl Friedrich von Siemens Stiftung, European Neuroendocrine Association and the Deutsche Gesellschaft fur Endokrinologie.
}

\section{References}

1 Etxabe J \& Vazquez JA. Morbidity and mortality in Cushing's disease: an epidemiological approach. Clinical Endocrinology 199440 479-484. (doi:10.1111/j.1365-2265.1994.tb02486.x)

2 Lindholm J, Juul S, Jørgensen JO, Astrup J, Bjerre P, FeldtRasmussen U, Hagen C, Jørgensen J, Kosteljanetz M, Kristensen L et al. Incidence and late prognosis of Cushing's syndrome: a populationbased study. Journal of Clinical Endocrinology and Metabolism 200186 117-123.

3 Ritzel K, Beuschlein F, Mickisch A, Osswald A, Schneider HJ, Schopohl J \& Reincke M. Clinical review: outcome of bilateral adrenalectomy in Cushing's syndrome: a systematic review. Journal of Clinical Endocrinology and Metabolism 201398 3939-3948. (doi:10.1210/ jc.2013-1470)

4 Oßwald A, Plomer E, Dimopoulou C, Milian M, Blaser R, Ritzel K, Mickisch A, Knerr F, Stanojevic M, Hallfeldt K et al. Favorable long-term outcomes of bilateral adrenalectomy in Cushing's disease. European Journal of Endocrinology 2014171 209-215. (doi:10.1530/EJE-14-0214)

5 Iacobone M, Albiger N, Scaroni C, Mantero F, Fassina A, Viel G, Frego M $\&$ Favia G. The role of unilateral adrenalectomy in ACTH-independent macronodular adrenal hyperplasia (AIMAH). World Journal of Surgery 200832 882-889. (doi:10.1007/s00268-007-9408-5)

6 Xu Y, Rui W, Qi Y, Zhang C, Zhao J, Wang X, Wu Y, Zhu Q, Shen Z, Ning $\mathrm{G}$ et al. The role of unilateral adrenalectomy in corticotropin-independent bilateral adrenocortical hyperplasias. World Journal of Surgery 201337 1626-1632. (doi:10.1007/s00268-0132059-9)

7 Biller BM, Grossman AB, Stewart PM, Melmed S, Bertagna X, Bertherat J, Buchfelder M, Colao A, Hermus AR, Hofland LJ et al. Treatment of adrenocorticotropin-dependent Cushing's syndrome: a consensus statement. Journal of Clinical Endocrinology and Metabolism 200893 2454-2462. (doi:10.1210/jc.2007-2734)

8 Petersenn S, Beckers A, Ferone D, Van der Lely AJ, Bollerslev J, Boscaro M, Brue T, Bruzzi P, Casanueva FF \& Chanson P. Therapy of endocrine disease: outcomes in patients with Cushing's disease undergoing transsphenoidal surgery: systematic review assessing criteria used to define remission and recurrence. European Journal of Endocrinology 2015172 R227-R239. (doi:10.1530/ EJE-14-0883)

9 Aniszewski JP, Young WF Jr, Thompson GB, Grant CS \& van Heerden JA. Cushing syndrome due to ectopic adrenocorticotropic hormone secretion. World Journal of Surgery 200125 934-940. (doi:10.1007/s00268-001-0032-5)

10 Ilias I, Torpy DJ, Pacak K, Mullen N, Wesley RA \& Nieman LK. Cushing's syndrome due to ectopic corticotropin secretion: twenty years' experience at the National Institutes of Health. Journal of Clinical Endocrinology and Metabolism 200590 4955-4962. (doi:10.1210/jc. 2004-2527)

11 Isidori AM, Kaltsas GA, Pozza C, Frajese V, Newell-Price J, Reznek RH, Jenkins PJ, Monson JP, Grossman AB \& Besser GM. The ectopic adrenocorticotropin syndrome: clinical features, diagnosis, management, and long-term follow-up. Journal of Clinical Endocrinology and Metabolism 200691 371-377. (doi:10.1210/jc.2005-1542)

12 Bertagna X \& Guignat L. Approach to the Cushing's disease patient with persistent/recurrent hypercortisolism after pituitary surgery. Journal of Clinical Endocrinology and Metabolism 201398 1307-1318. (doi:10.1210/jc.2012-3200)

13 Hofmann BM, Hlavac M, Kreutzer J, Grabenbauer G \& Fahlbusch R. Surgical treatment of recurrent Cushing's disease. Neurosurgery $2006 \mathbf{5 8}$ 1108-1118. (doi:10.1227/01.NEU.0000215945.26764.92)

14 Dimopoulou C, Schopohl J, Rachinger W, Buchfelder M, Honegger J, Reincke M \& Stalla GK. Long-term remission and recurrence rates after first and second transsphenoidal surgery for Cushing's disease: care reality in the Munich Metropolitan Region. 
European Journal of Endocrinology 2013170 283-292. (doi:10.1530/EJE13-0634)

15 Estrada J, Boronat M, Mielgo M, Magallon R, Millan I, Diez S, Lucas T \& Barcelo B. The long-term outcome of pituitary irradiation after unsuccessful transsphenoidal surgery in Cushing's disease. New England Journal of Medicine 1997336 172-177. (doi:10.1056/ NEJM199701163360303)

16 Castinetti F, Morange I, Conte-Devolx B \& Brue T. Cushing's disease. Orphanet Journal of Rare Diseases 20127 41. (doi:10.1186/1750-11727-41)

17 Castinetti F, Regis J, Dufour H \& Brue T. Role of stereotactic radiosurgery in the management of pituitary adenomas. Nature Reviews. Endocrinology 20106 214-223. (doi:10.1038/nrendo.2010.4)

18 Pivonello R, De Martino MC, Cappabianca P, De Leo M, Faggiano A, Lombardi G, Hofland LJ \& Colao A. The medical treatment of Cushing's disease: effectiveness of chronic treatment with the dopamine agonist cabergoline in patients unsuccessfully treated by surgery. Journal of Clinical Endocrinology and Metabolism 200994 223-230. (doi:10.1210/ jc.2008-1533)

19 Colao A, Petersenn S, Newell-Price J, Findling JW, Gu F, Maldonado M, Schoenherr U, Mills D, Salgado LR \& Biller BM. Pasireotide B2305 Study Group. A 12-month phase 3 study of pasireotide in Cushing's disease. New England Journal of Medicine 2012366 914-924. (doi:10.1056/ NEJMoa1105743)

20 Bertagna X, Pivonello R, Fleseriu M, Zhang Y, Robinson P, Taylor A, Watson CE, Maldonado M, Hamrahian AH, Boscaro M et al. LCI699, a potent 11ß-hydroxylase inhibitor, normalizes urinary cortisol in patients with Cushing's disease: results from a multicenter, proofof-concept study. Journal of Clinical Endocrinology and Metabolism 2014 99 1375-1383. (doi:10.1210/jc.2013-2117)

21 Daniel E \& Newell-Price J. Therapy of endocrine disease: steroidogenesis enzyme inhibitors in Cushing's syndrome. European Journal of Endocrinology 2015172 R263-R280. (doi:10.1530/EJE-14-1014)

22 Baudry C, Coste J, Bou Khalil R, Silvera S, Guignat L, Guibourdenche J, Abbas H, Legmann P, Bertagna X \& Bertherat J. Efficiency and tolerance of mitotane in Cushing's disease in 76 patients from a single center. European Journal of Endocrinology 2012167 473-481. (doi:10.1530/EJE12-0358)

23 Kamenický P, Droumaguet C, Salenave S, Blanchard A, Jublanc C, Gautier JF, Brailly-Tabard S, Leboulleux S, Schlumberger M, Baudin E et al. Mitotane, metyrapone, and ketoconazole combination therapy as an alternative to rescue adrenalectomy for severe ACTH-dependent Cushing's syndrome. Journal of Clinical Endocrinology and Metabolism 201196 2796-2804. (doi:10.1210/jc.2011-0536)

24 Donadille B, Groussin L, Waintrop C, Abbas H, Tenenbaum F, Dugué MA, Coste J, Bertagna X \& Bertherat J. Management of Cushing's syndrome due to ectopic adrenocorticotropin secretion with 1,ortho-1, para'-dichloro-diphenyl-dichloro-ethane: findings in 23 patients from a single center. Journal of Clinical Endocrinology and Metabolism 201095 537-544. (doi:10.1210/jc.2009-1317)

25 Fleseriu M, Biller BM, Findling JW, Molitch ME, Schteingart DE, Gross C $\&$ SEISMIC Study Investigators. Mifepristone, a glucocorticoid receptor antagonist, produces clinical and metabolic benefits in patients with Cushing's syndrome. Journal of Clinical Endocrinology and Metabolism 201297 2039-2049. (doi:10.1210/jc.2011-3350)

26 Feelders RA, de Bruin C, Pereira AM, Romijn JA, Netea-Maier RT, Hermus AR, Zelissen PM, van Heerebeek R, de Jong FH, van der Lely AJ, Lamberts SW et al. Pasireotide alone or with cabergoline and ketoconazole in Cushing's disease. New England Journal of Medicine 2010 362 1846-1848. (doi:10.1056/NEJMc1000094)

27 Sarlis NJ, Chanock SJ \& Nieman LK. Cortisolemic indices predict severe infections in Cushing syndrome due to ectopic production of adrenocorticotropin. Journal of Clinical Endocrinology and Metabolism $20008542-47$.

28 Ntali G, Asimakopoulou A, Siamatras T, Komninos J, Vassiliadi D, Tzanela M, Tsagarakis S, Grossman AB, Wass JA \& Karavitaki N.
Mortality in Cushing's syndrome: systematic analysis of a large series with prolonged follow-up. European Journal of Endocrinology 2013169 715-723. (doi:10.1530/EJE-13-0569)

29 Gkourogianni A, Lodish MB, Zilbermint M, Lyssikatos C, Belyavskaya E, Keil MF \& Stratakis CA. Death in pediatric Cushing syndrome is uncommon but still occurs. European Journal of Pediatrics 2015174 501-507. (doi:10.1007/s00431-014-2427-y)

30 Morris LF, Harris RS, Milton DR, Waguespack SG, Habra MA, Jimenez C, Vassilopoulou-Sellin R, Lee JE, Perrier ND \& Grubbs EG. Impact and timing of bilateral adrenalectomy for refractory adrenocorticotropic hormone-dependent Cushing's syndrome. Surgery $2013 \mathbf{1 5 4}$ 1174-1183. (doi:10.1016/j.surg.2013.06.017)

31 Preda VA, Sen J, Karavitaki N \& Grossman AB. Etomidate in the management of hypercortisolaemia in Cushing's syndrome: a review. European Journal of Endocrinology 2012167 137-143. (doi:10.1530/ EJE-12-0746)

32 Allolio B, Schulte HM, Kaulen D, Reincke M, Jaursch-Hancke C \& Winkelmann W. Nonhypnotic low-dose etomidate for rapid correction of hypercortisolaemia in Cushing's syndrome. Klinische Wochenschrift 198866 361-364. (doi:10.1007/BF01735795)

33 Soh LM, Gunganah K, Akker SA, Jones P, Khachi H, Dodzo K \& Drake WM. Etomidate in the emergency management of hypercortisolemia. European Journal of Endocrinology 2012167 727-728. (doi:10.1530/EJE-12-0698)

34 Corcuff JB, Young J, Masquefa-Giraud P, Chanson P, Baudin E \& Tabarin A. Rapid control of severe neoplastic hypercortisolism with metyrapone and ketoconazole. European Journal of Endocrinology 2015 172 473-481. (doi:10.1530/EJE-14-0913)

35 Gagner M, Lacroix A \& Bolté E. Laparoscopic adrenalectomy in Cushing's syndrome and pheochromocytoma. New England Journal of Medicine 1992327 1033. (doi:10.1056/ NEJM199210013271417)

36 Acosta E, Pantoja JP, Gamino R, Rull JA \& Herrera MF. Laparoscopic versus open adrenalectomy in Cushing's syndrome and disease. Surgery 1999126 1111-1116. (doi:10.1067/msy.2099.102423)

37 Porpiglia F, Fiori C, Bovio S, Destefanis P, Alì A, Terrone C, Fontana D, Scarpa RM, Tempia A \& Terzolo M. Bilateral adrenalectomy for Cushing's syndrome: a comparison between laparoscopy and open surgery. Journal of Endocrinological Investigation 200427 654-658. (doi:10.1007/BF03347498)

38 Smith PW, Turza KC, Carter CO, Vance ML, Laws ER \& Hanks JB. Bilateral adrenalectomy for refractory Cushing disease: a safe and definitive therapy. Journal of the American College of Surgeons 2009208 1059-1064. (doi:10.1016/j.jamcollsurg.2009.02.054)

39 Lee CR, Walz MK, Park S, Park JH, Jeong JS, Lee SH, Kang SW, Jeong JJ, Nam KH \& Chung WY. A comparative study of the transperitoneal and posterior retroperitoneal approaches for laparoscopic adrenalectomy for adrenal tumours. Annals of Surgical Oncology 201219 2629-2634. (doi:10.1245/s10434-012-2352-0)

40 Kissane NA \& Cendan JC. Patients with Cushing's syndrome are careintensive even in the era of laparoscopic adrenalectomy. American Surgeon 200975 279-283.

41 Sippel RS, Elaraj DM, Kebebew E, Lindsay S, Tyrrell JB \& Duh QY. Waiting for change: symptom resolution after adrenalectomy for Cushing's syndrome. Surgery $2008 \mathbf{1 4 4}$ 1054-1060. (doi:10.1016/ j.surg.2008.08.024)

42 Raffaelli M, Brunaud L, De Crea C, Hoche G, Oragano L, Bresler L, Bellantone R \& Lombardi CP. Synchronous bilateral adrenalectomy for Cushing's syndrome: laparoscopic versus posterior retroperitoneoscopic versus robotic approach. World Journal of Surgery 201438 709-715. (doi:10.1007/s00268-013-2326-9)

43 Hawn MT, Cook D, Deveney C \& Sheppard BC. Quality of life after laparoscopic bilateral adrenalectomy for Cushing's disease. Surgery 2002132 1064-1068. (doi:10.1067/msy.2002.128482)

44 Thompson SK, Hayman AV, Ludlam WH, Deveney CW, Loriaux DL \& Sheppard BC. Improved quality of life after bilateral 
laparoscopic adrenalectomy for Cushing's disease: a 10-year experience. Annals of Surgery 2007245 790-794. (doi:10.1097/01.sla. $0000251578.03883 .2 \mathrm{f}$ )

45 Allolio B. Extensive expertise in endocrinology: adrenal crisis. European Journal of Endocrinology 2015172 R115-R124. (doi:10.1530/ EJE-14-0824)

46 Hahner S, Loeffler M, Bleicken B, Drechsler C, Milovanovic D, Fassnacht M, Ventz M, Quinkler M \& Allolio B. Epidemiology of adrenal crisis in chronic adrenal insufficiency: the need for new prevention strategies. European Journal of Endocrinology 2010162 597-602. (doi:10.1530/EJE-09-0884)

47 Hahner S, Spinnler C, Fassnacht M, Burger-Stritt S, Lang K, Milovanovic D, Beuschlein F, Willenberg HS, Quinkler M \& Allolio B. High incidence of adrenal crisis in educated patients with chronic adrenal insufficiency - a prospective study. Journal of Clinical Endocrinology and Metabolism 2015100 407-416. (doi:10.1210/ jc.2014-3191)
48 Reisch N, Willige M, Kohn D, Schwarz HP, Allolio B, Reincke M, Quinkler M, Hahner S \& Beuschlein F. Frequency and causes of adrenal crises over lifetime in patients with 21-hydroxylase deficiency. European Journal of Endocrinology 2012167 35-42. (doi:10.1530/ EJE-12-0161)

49 Barber TM, Adams E, Ansorge O, Byrne JV, Karavitaki N \& Wass JA. Nelson's syndrome. European Journal of Endocrinology 2010163 495-507. (doi:10.1530/EJE-10-0466)

50 Nagesser SK, van Seters AP, Kievit J, Hermans J, Krans HM \& van de Velde CJ. Long-term results of total adrenalectomy for Cushing's disease. World Journal of Surgery 200024 108-113. (doi:10.1007/ s002689910020)

51 Assié G, Bahurel H, Coste J, Silvera S, Kujas M, Dugué MA, Karray F, Dousset B, Bertherat J, Legmann P et al. Corticotroph tumor progression after adrenalectomy in Cushing's disease: a reappraisal of Nelson's Syndrome. Journal of Clinical Endocrinology and Metabolism 200792 172-179.

Received 7 March 2015

Revised version received 16 May 2015

Accepted 20 May 2015 